\title{
Numerical study of bracing section variations in an eccentrically braced frame
}

\author{
Sabril Haris ${ }^{1, *}$, Nidiasari $^{1}$, and Sonya Triaz Pramadhani Putri ${ }^{1}$ \\ ${ }^{1}$ Civil Engineering Departement, Faculty of Engineering, Universitas Andalas, Indonesia
}

\begin{abstract}
Eccentrically Braced Frame (EBF) is a better option for the earthquake-prone country due to it having a better strength, stiffness, energy dissipation and ductility than Moment Resisting Frame (MRF) structure and more so than structures made of concrete. The structure's ductility was influenced by the cross-sectional dimension and link element of the frame. This study aims to determine the relation behavior of EBF with the varied link element and cross-sectional of bracing with the ultimate load and ductility of the structure. The analysis was done using MSC. PATRAN/NASTRAN student edition software. A total of three-link model variations, each one represents the three-link variations of EBF; short link, intermediate link, and long link. As for the cross-sectional, variation was made on the flange and web thickness of the IWF profile and web thickness of the HSS profile. The most optimum performance of the structure was determined by displacement control and static monotonic loading. The result indicates that variations in the crosssectional of bracing effects the short link EBF the most, while the intermediate and long link EBF doesn't show a significant change in terms of ultimate load. Meanwhile, ductility is not bound by the increase of bracing thickness.
\end{abstract}

\section{Introduction}

Indonesia is one of the countries with a high intensity of earthquakes caused by its geographical location, which is between 3 earthen plates; Indo-Australian, Euroasia, and Pacific. These earthquakes caused damages in concrete buildings and infrastructure. Therefore people have changed their structural components from concrete to steel structure or become a composite structure.

The steel structure has a few benefits compared to the concrete structure, such as lightweight, stiffness, fabricated, and relatively easier to build. In buildings, the steel structure can be formed as a frame, which is a system composed of structural sections connected that are used to resisting load as one completed structure with and without horizontal diaphragms or plates system. There are three types of the frame: Moment Resisting Frame (MRF), Concentrically Braced Frame (CBF), and Eccentrically Braced Frame (EBF) [1,2,3]. The types of the frames are shown in Fig.1.[4]. Each type has different behavior as well as strength and ductility, but for the earthquake-prone country, EBF has the best value in both aspects. [1,2]

EBF has been proven to be the best in strength, stiffness, ductility, and energy dissipation system compared to the other frames [1]. In EBF, ductility value can be determined when the link element of EBF yielded without having the other elements such as column and beam to yield as well. While the link element gives better stiffness than MRF, the longer the link element, the structure's lateral stiffness decreases, whereas the structure becomes more flexible.

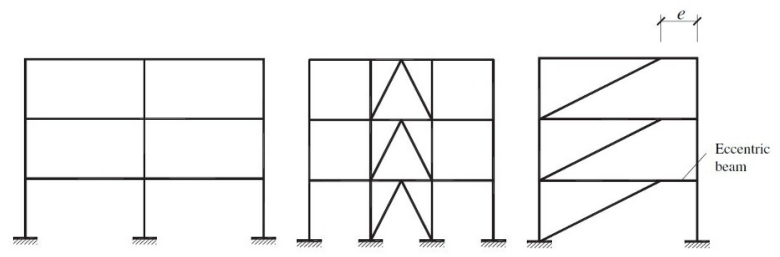

Fig. 1. Steel Frame Structure (MRF,CBF,EBF) [4]

EBF has been proven to be the best in strength, stiffness, ductility, and energy dissipation system compared to the other frames [1]. In EBF, ductility value can be determined when the link element of EBF yielded without having the other elements such as column and beam to yield as well. While the link element gives better stiffness than MRF, the longer the link element, the structure's lateral stiffness decreases, whereas the structure becomes more flexible.

In EBF frames, a distance is either created between the two ends of the bracing member and the column or between the bracing member and the beam, as shown in Fig. 2. The distance is called link (e). The link element provides a weak section in the frame for plastic deformation capacity and energy dissipation released by earthquake.

\footnotetext{
* Corresponding author: sabril.haris@eng.unand.ac.id
} 

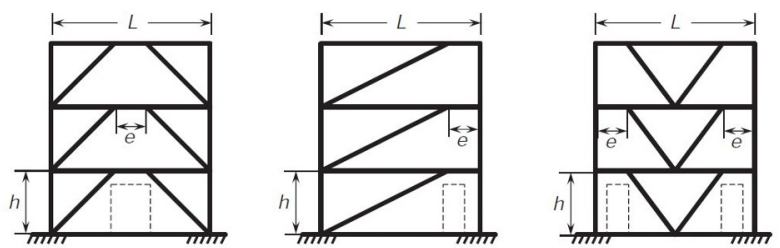

Fig. 2. Eccentrically Braced Frame Variations [1].

Eccentrically Braced Frame (EBF) divided on its yielding behavior [5];

a. Shear Link (Short Link), e $\leq 1,6 \mathrm{M}_{\mathrm{p}} / \mathrm{V}_{\mathrm{p}}$.

This link yield because of shear on response/inelastic deformation.

b. Shear Dominant Link (Intermediate Link), 1,6 $\mathrm{M}_{\mathrm{p}} / \mathrm{V}_{\mathrm{p}}$ $\leq \mathrm{e} \leq 2,6 \mathrm{M}_{\mathrm{p}} / \mathrm{V}_{\mathrm{p}}$

This link yield because of shear dominant (on a combination of shear and flexural) on response/inelastic deformation.

c. Flexural Dominant Link (Long Link), $2,6 \mathrm{M}_{\mathrm{p}} / \mathrm{V}_{\mathrm{p}} \leq \mathrm{e}$ $\leq 5 \mathrm{M}_{\mathrm{p}} / \mathrm{V}_{\mathrm{p}}$

This link yield because of flexural dominant (on a combination of shear and flexural) on response/inelastic deformation.

d. Flexural Link, $\mathrm{e} \geq 5 \mathrm{M}_{\mathrm{p}} / \mathrm{V}_{\mathrm{p}}$

This link yield because of flexural on response/inelastic deformation.

where :

$\mathrm{M}_{\mathrm{p}}$ is nominal plastic moment capacity (Nmm); $\mathrm{V}_{\mathrm{p}}$ is nominal plastic shear capacity, $(\mathrm{N})$; e is Link length, (mm)

The plastic moment and shear capacity [6] expressed as:

$$
\begin{gathered}
M_{p}=Z_{x} \cdot f_{y} \\
V_{p}=0,6 \cdot f_{y} \cdot t_{w} \cdot t_{f}
\end{gathered}
$$

where :

$\mathrm{M}_{\mathrm{p}}$ is nominal plastic moment capacity $(\mathrm{Nmm}) ; Z_{\mathrm{x}}$ is plasticity modulus of the section $\left(\mathrm{mm}^{3}\right)$ : is the specified minimum yield strength $(\mathrm{MPa}): \mathrm{V}_{\mathrm{p}}$ is the plastic shear force of the section $(\mathrm{N})$; is $t_{\mathrm{f}}$ the flange thickness $(\mathrm{mm}) ; \mathrm{t}_{\mathrm{w}}$ : the web thickness $(\mathrm{mm})$

In this paper, the effect of variation of the bracing section on eccentrically braced frame's ultimate load, ultimate displacement, and ductility will be analysed.

\section{Model Analysis}

The structure analysed in this paper is eccentrically braced frames of short link, intermediate link, and long link. IWF 400.200.8.13 type of steel is used for modeling the column and beam, while the bracing is using IWF 200.100.5,5.8 and HSS 200.100.4,5 variants. The column height is $3,5 \mathrm{~m}$, and the length of the beam is $6 \mathrm{~m}$.

The link lengths used are a short, intermediate, and long link. Using limit of each variant links as defined in the chapter before, the $\mathrm{M}_{\mathrm{p}} / \mathrm{V}_{\mathrm{p}}$ is $716.327 \mathrm{~mm}$, therefore the lengths of each link used are $600 \mathrm{~mm}$ for the short link, $1500 \mathrm{~mm}$ for the intermediate link, and $2800 \mathrm{~mm}$ for the long link (Fig. 3-5). Variations of the bracing thickness are listed in Table 1.

Structural element used for designing the model are :

- Elasticity modulus : $200.000 \mathrm{MPa}$

- Poisson ratio : 0.3

- Shear modulus $\quad: 80.000 \mathrm{MPa}$

- Steel density $\quad: 7850 \mathrm{~kg} / \mathrm{m}^{3}$

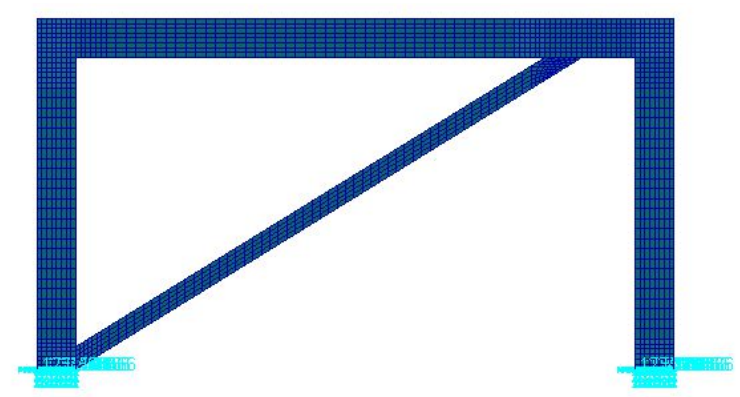

Fig. 3. Model Structure of Short Link $(\mathrm{e}=600 \mathrm{~mm})$

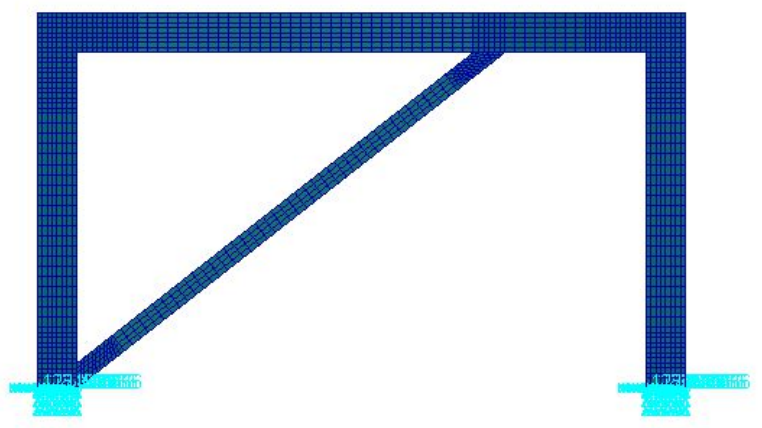

Fig. 4. Model Structure of Intermediate Link $(\mathrm{e}=1500 \mathrm{~mm})$

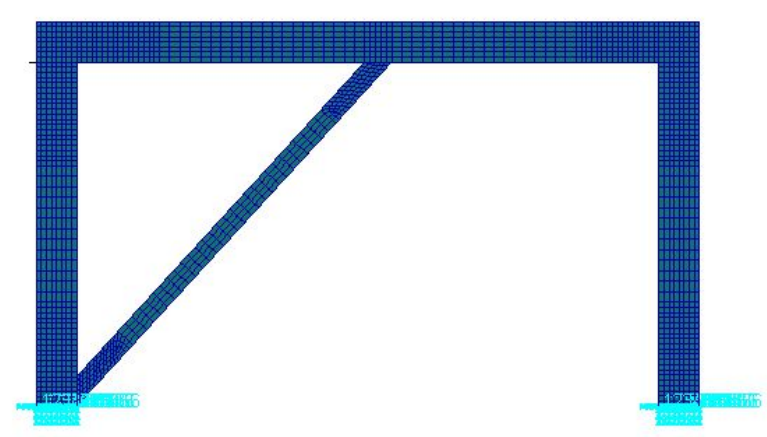

Fig. 5. Model Structure of Long Link $(e=2800 \mathrm{~mm})$

Computer package program MSC. Patran is used to create three models of eccentrically braced frames, and each one represents a short link, intermediate link, and long link. The structure is modeled by finite element QUAD4 using MSC. Nastran and Patran, therefore, the structural section are changed from the original profile. In this case, the outer part of the section's neutral line acts as the base in which it will remain unchanged even if the thickness of the section increase (Fig. 6 -7). 
Table 1.Variation of bracing used for analysis

\begin{tabular}{|c|c|c|c|c|}
\hline \multirow{2}{*}{$\begin{array}{c}\text { Variant } \\
\text { No. }\end{array}$} & \multicolumn{4}{|c|}{ IWF section } \\
\hline & $\mathrm{h}$ & $\mathrm{b}$ & $t_{w}$ & $t_{f}$ \\
\hline 1 & \multirow{6}{*}{200} & \multirow{6}{*}{100} & \multirow{6}{*}{5.5} & 8 \\
\hline 2 & & & & 10 \\
\hline 3 & & & & 12 \\
\hline 4 & & & & 14 \\
\hline 5 & & & & 16 \\
\hline 6 & & & & 18 \\
\hline 7 & \multirow{6}{*}{200} & \multirow{6}{*}{100} & 5.5 & \multirow{6}{*}{8} \\
\hline 8 & & & 7.5 & \\
\hline 9 & & & 9.5 & \\
\hline 10 & & & 11.5 & \\
\hline 11 & & & 13.5 & \\
\hline 12 & & & 15.5 & \\
\hline \multicolumn{5}{|c|}{ HSS section } \\
\hline 13 & \multirow{8}{*}{200} & \multirow{8}{*}{100} & 4.5 & \multirow{8}{*}{ - } \\
\hline 14 & & & 5 & \\
\hline 15 & & & 5.5 & \\
\hline 16 & & & 6 & \\
\hline 17 & & & 6.5 & \\
\hline 18 & & & 7 & \\
\hline 19 & & & 7.5 & \\
\hline 20 & & & 8 & \\
\hline
\end{tabular}

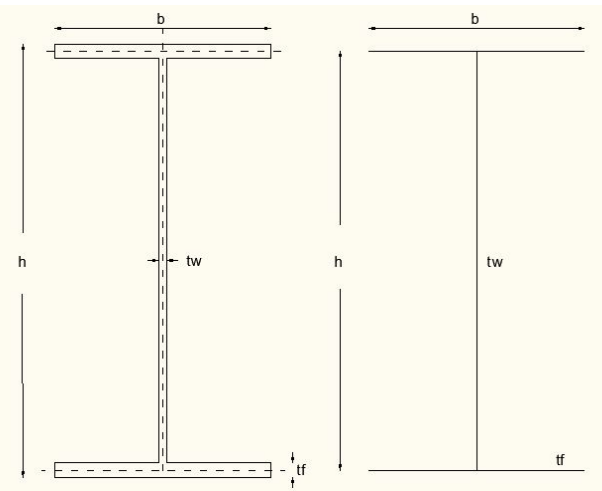

Fig. 6. Ratio of Actual IWF and Model Section
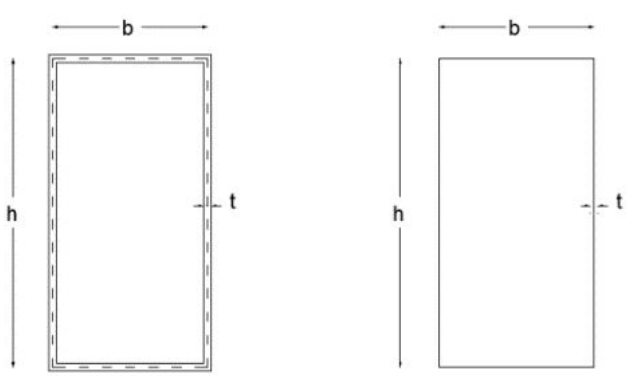

Fig. 7. Ratio of Actual HSS and Model Section

Monotonic loading is used for the structures by applying the load on a few nodes at the end of the beam, as seen in Fig.8, with incremental displacement.

The static monotonic loading is controlled in each phase of loadings, as seen in Fig. 9. In this paper, displacement control is used to get a clear response of the structure when the ultimate loading occurs.

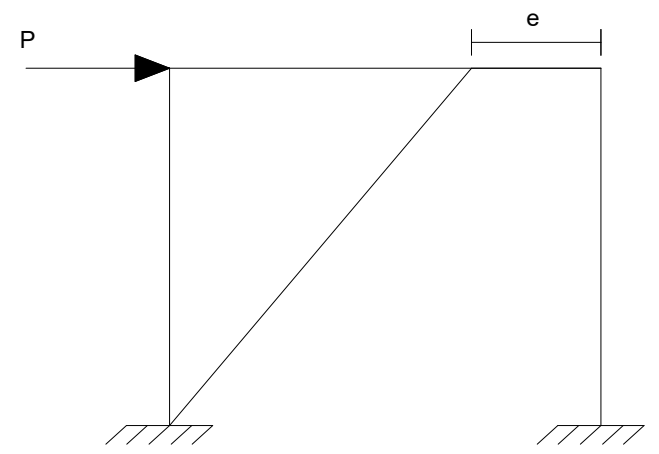

Fig. 8. Structure Loading

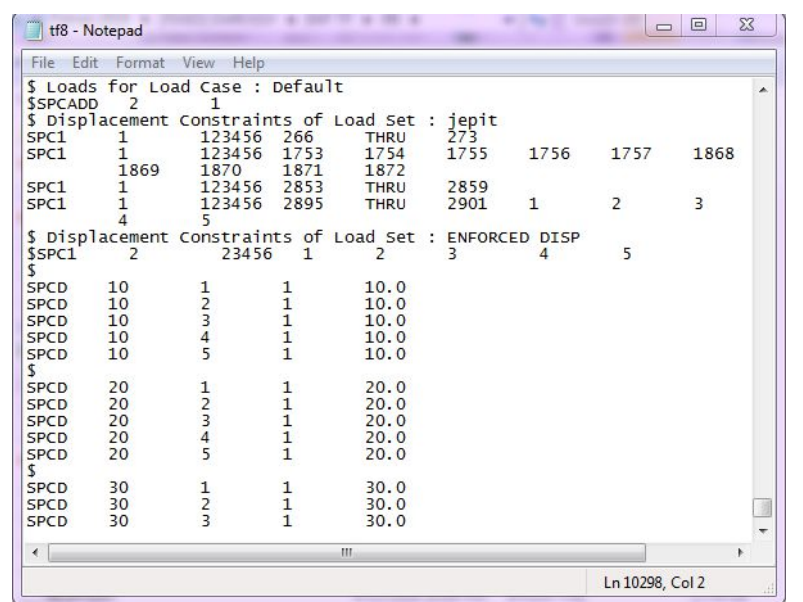

Fig. 9. Structure Loading with Displacement Control

The structure that has been variated in terms of bracing section each executed using MSC. Nastran to get the data needed for analysis.

\section{Result and Analysis}

\subsection{Structural Behavior in Bracing Section Variation}

Analysis results for numerical modeling of eccentrically braced frame with bracing section variation in short, intermediate, and long link using finite element method and displacement control of MSC. Nastran and MSC. Patran are shown in Fig. 10 and Table 2.

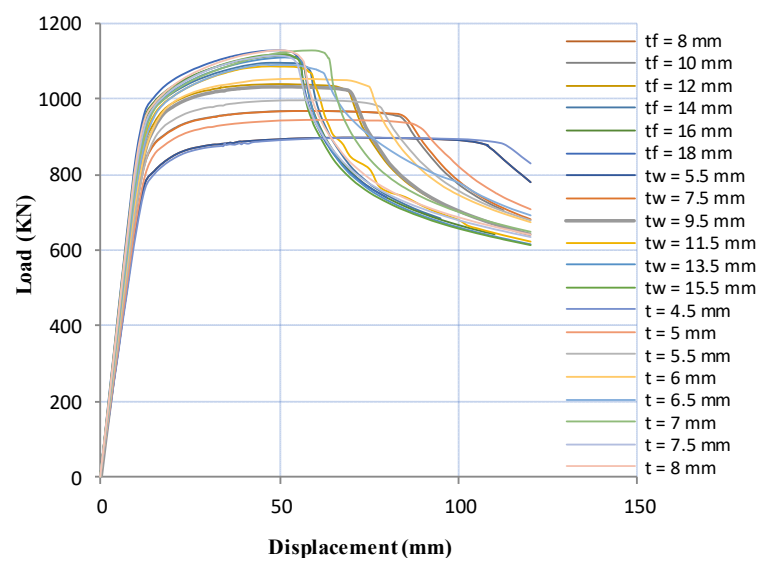

Fig. 10. Displacement vs. Load in IWF and HSS Cross-Section Variated in Short Link EBF. 
From Table 2, the lowest ultimate load for short link EBF $(\mathrm{e}=600 \mathrm{~mm})$ shows in HSS variated bracing section of $4.5 \mathrm{~mm}$ in thickness; $895.149 \mathrm{kN}$, slightly lower than IWF's, and the ultimate displacement is $77.241 \mathrm{~mm}$. The short link structure's ductility is not bound by the increasing of bracing thickness nor the change of bracing types from HSS to IWF.

Table 2. Summary of Bracing Section Variation for Short Link

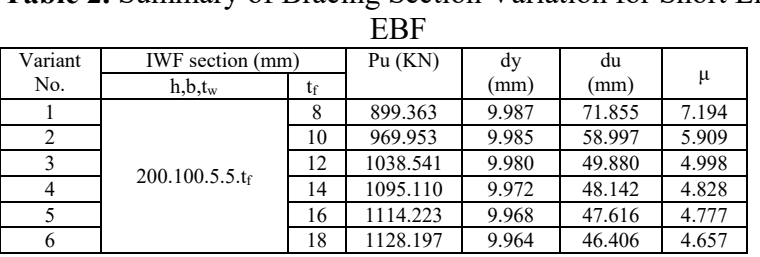

\begin{tabular}{|c|c|c|c|c|c|c|}
\hline \multirow{2}{*}{$\begin{array}{c}\text { Variant } \\
\text { No. }\end{array}$} & \multicolumn{2}{|c|}{ IWF section (mm) } & \multirow[t]{2}{*}{$\mathrm{Pu}(\mathrm{KN})$} & \multirow{2}{*}{$\begin{array}{c}\begin{array}{c}\mathrm{dy} \\
(\mathrm{mm})\end{array} \\
\text { (a) }\end{array}$} & \multirow{2}{*}{$\begin{array}{c}\mathrm{du} \\
(\mathrm{mm})\end{array}$} & \multirow[b]{2}{*}{$\mu$} \\
\hline & h.b.t.tf & $t_{w}$ & & & & \\
\hline & \multirow{6}{*}{ 200.100.tw. 8} & 5.5 & 899.363 & 9.987 & 71.855 & 7.194 \\
\hline 8 & & 7.5 & 966.363 & 9.984 & 58.696 & 5.879 \\
\hline 9 & & $\begin{array}{l}9.5 \\
\end{array}$ & 1032.027 & 9.975 & 51.130 & 5.126 \\
\hline 10 & & 11.5 & 1086.701 & 9.965 & 47.475 & 4.764 \\
\hline 11 & & 13.5 & 1114,744 & 9.959 & 47.192 & 4.739 \\
\hline 12 & & 15.5 & 1119.620 & 9.952 & 46.864 & 4.709 \\
\hline
\end{tabular}

\begin{tabular}{|c|c|c|c|c|c|c|}
\hline \multirow{2}{*}{$\begin{array}{c}\text { Variant } \\
\text { No. }\end{array}$} & \multicolumn{2}{|c|}{ IWF section (mm) } & \multirow[t]{2}{*}{$\mathrm{Pu}(\mathrm{KN})$} & \multirow{2}{*}{$\begin{array}{c}\mathrm{dy} \\
(\mathrm{mm})\end{array}$} & \multirow{2}{*}{$\begin{array}{c}\mathrm{du} \\
(\mathrm{mm})\end{array}$} & \multirow[b]{2}{*}{$\mu$} \\
\hline & $\mathrm{h}, \mathrm{b}$ & $t_{w}$ & & & & \\
\hline 13 & \multirow{8}{*}{$200.100 . \mathrm{t}$} & 4.5 & 895.149 & 9.979 & 77.241 & 7.741 \\
\hline 14 & & 5 & 944.248 & 9.977 & 63.383 & 6.353 \\
\hline 15 & & 5.5 & 997.254 & 9.975 & 55.666 & 5.581 \\
\hline 16 & & 6 & 1053.277 & \begin{tabular}{|l|l|}
9.973 \\
\end{tabular} & \begin{tabular}{|l|l|}
54.333 \\
\end{tabular} & 5.448 \\
\hline 17 & & 6.5 & 1090.777 & 9.971 & 48.930 & 4.907 \\
\hline 18 & & 7 & 1126.510 & 9.970 & 55.235 & 5.540 \\
\hline 19 & & 7.5 & 1114.649 & 9.967 & 46.305 & 4.646 \\
\hline 20 & & 8 & 1127.723 & 15.019 & 46.399 & 3.089 \\
\hline
\end{tabular}

Meanwhile, the highest ductility appears at the thinnest bracing section of HSS at 7.741. We can see that the increase of bracing thickness will increases the ultimate loads of the structure quite significantly and decreases the ultimate displacement. It can be seen that the thicker the bracing section, the structure becomes stiffer, whereas the ultimate displacement decreases. The three variations have the same type of increment in ultimate loads, as shown in the graphic below.

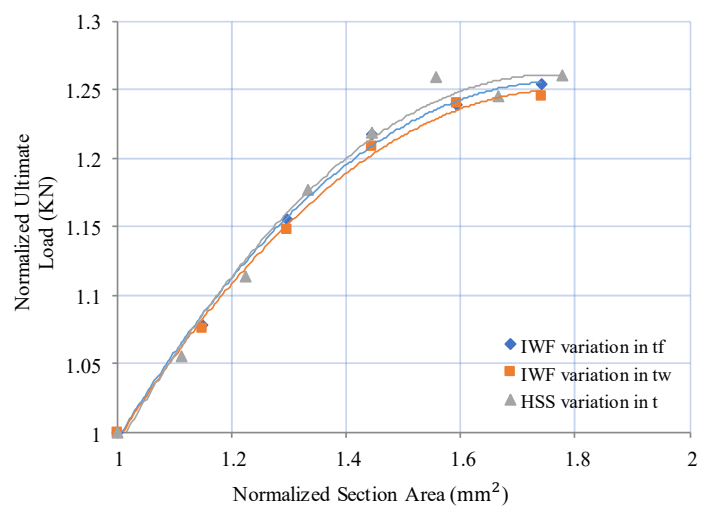

Fig. 11. Normalized Ultimate Load vs. Section Area for Short Link EBF

From the graphics above, we can see that flange variation is the best variation of the bracing section for short link EBF. Increasing the bracing section increases the ultimate loads quite a lot. While changing the section profile from IWF to HSS doesn't change the ultimate loads significantly in ultimate loads, in term of ductility, it changes impactful as it has the different line variation from flange and web variated IWF.

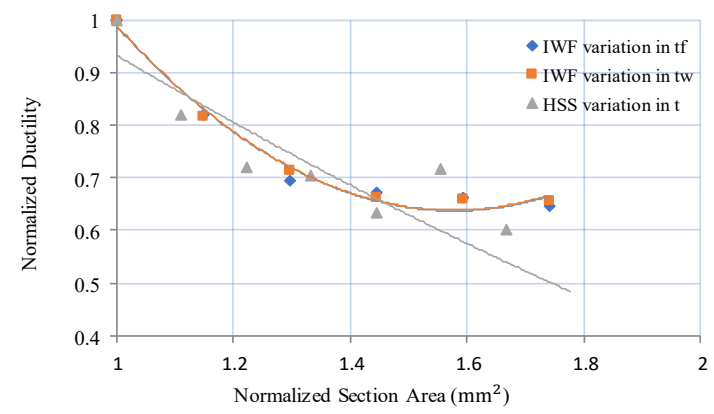

Fig. 12. Normalized Ductility vs. Section Area for Short Link EBF

Table 3. Recapitulation of Bracing Section Variation for Intermediate Link EBF

\begin{tabular}{|c|c|c|c|c|c|c|}
\hline \multirow{2}{*}{$\begin{array}{l}\text { Variant } \\
\text { No. }\end{array}$} & \multicolumn{2}{|c|}{ IWF section (mm) } & \multirow{2}{*}{$\mathrm{Pu}(\mathrm{KN})$} & \multirow{2}{*}{$\begin{array}{c}\text { dy } \\
(\mathrm{mm})\end{array}$} & \multirow{2}{*}{$\begin{array}{c}\mathrm{du} \\
(\mathrm{mm})\end{array}$} & \multirow[b]{2}{*}{$\mu$} \\
\hline & h.b.t. $t_{w}$ & $t_{f}$ & & & & \\
\hline 21 & \multirow{6}{*}{$\begin{array}{c}200.100 .5 .5 . t \\
\mathrm{f}\end{array}$} & 8 & 813.252 & 9.999 & 35.892 & 3.590 \\
\hline 22 & & 10 & 831.859 & 9.998 & 24.975 & 2.498 \\
\hline 23 & & 12 & 845.052 & 9.997 & 24.869 & 2.488 \\
\hline 24 & & 14 & 856.554 & 9.995 & 24.244 & 2.526 \\
\hline 25 & & 16 & 866.642 & 9.993 & 27.128 & 2.715 \\
\hline 26 & & 18 & 870.805 & 9.992 & 25.733 & 2.575 \\
\hline
\end{tabular}

\begin{tabular}{|c|c|c|c|c|c|c|}
\hline \multirow{2}{*}{$\begin{array}{c}\text { Variant } \\
\text { No. }\end{array}$} & \multicolumn{2}{|c|}{ IWF section (mm) } & \multirow{2}{*}{$\begin{array}{c}\mathrm{Pu} \\
(\mathrm{KN})\end{array}$} & \multirow{2}{*}{$\begin{array}{c}\mathrm{dy} \\
(\mathrm{mm})\end{array}$} & \multirow{2}{*}{$\begin{array}{c}\mathrm{du} \\
(\mathrm{mm})\end{array}$} & \multirow[b]{2}{*}{$\mu$} \\
\hline & h.b.tf & $t_{w}$ & & & & \\
\hline 27 & \multirow{6}{*}{$200.100 . t_{\mathrm{w}} .8$} & 5.5 & 813.252 & 9.999 & 35.892 & 3.590 \\
\hline 28 & & 7.5 & 818.540 & 9.998 & 25.020 & 2.503 \\
\hline 29 & & 9.5 & 832.880 & 9.997 & 24.551 & 2.456 \\
\hline 30 & & 11.5 & 851.098 & 9.995 & 25.384 & 2.540 \\
\hline 31 & & 13.5 & 862.471 & 9.993 & 26.232 & 2.625 \\
\hline 32 & & 15.5 & 857.033 & 9.992 & 25.393 & 2.541 \\
\hline
\end{tabular}

\begin{tabular}{|c|c|c|c|c|c|c|}
\hline \multirow{2}{*}{$\begin{array}{c}\text { Variant } \\
\text { No. }\end{array}$} & \multicolumn{2}{|c|}{ IWF section $(\mathrm{mm})$} & \multirow{2}{*}{$\begin{array}{c}\mathrm{Pu} \\
(\mathrm{KN})\end{array}$} & \multirow{2}{*}{$\begin{array}{c}\mathrm{dy} \\
(\mathrm{mm})\end{array}$} & \multirow{2}{*}{$\begin{array}{c}\mathrm{du} \\
(\mathrm{mm})\end{array}$} & \multirow[b]{2}{*}{$\mu$} \\
\hline & h,b & $t_{w}$ & & & & \\
\hline 33 & \multirow{8}{*}{$200.100 . t$} & 4.5 & 806.200 & 9.985 & 40.359 & 4.042 \\
\hline 34 & & 5 & 816.501 & 9.987 & 31.051 & 3.109 \\
\hline 35 & & 5.5 & 825.740 & 9.987 & 28.618 & 2.866 \\
\hline 36 & & 6 & 829.326 & 9.986 & 28.439 & 2.848 \\
\hline 37 & & 6.5 & 836.290 & 9.986 & 27.016 & 2.705 \\
\hline 38 & & 7 & 833.031 & 9.985 & 27.018 & 2.706 \\
\hline 39 & & 7.5 & 841.786 & 9.984 & 27.058 & 2.710 \\
\hline 40 & & 8 & 842.999 & 9.983 & 26.588 & 2.663 \\
\hline
\end{tabular}

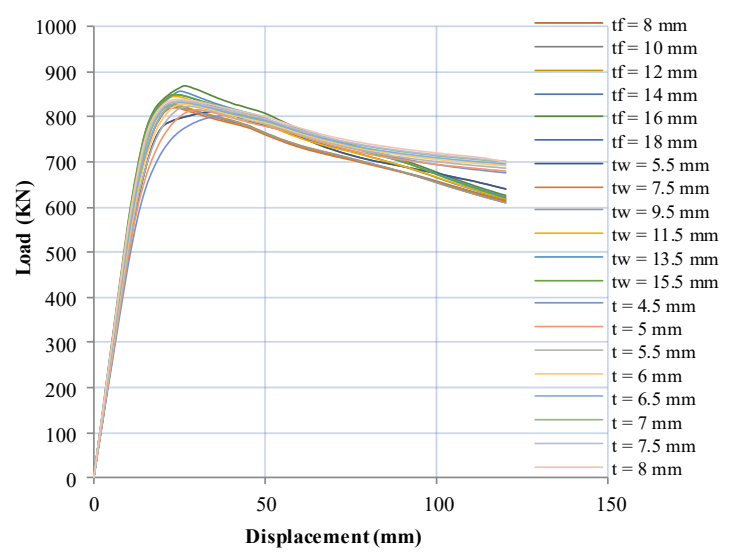

Fig. 13. Displacement vs. Load in IWF and HSS Cross-Section Profile Variated in Intermediate Link EBF.

The intermediate link EBF $(\mathrm{e}=1500 \mathrm{~mm})$ has the same behavior as a short link. The increase of bracing thickness increases the ultimate load and tends to decrease the ultimate displacement of the structure. The structure's highest ductility also appears at the thinnest bracing for the HSS variated structure at $4.5 \mathrm{~mm}$ at the 
value of 4.042. While the short link has the lowest ultimate load of 895.149 , in the intermediate link EBF, it decreases to $806.200 \mathrm{kN}$. The three variations (flange and web thickness of IWF and web thickness of HSS) have the same type of increment of ultimate loads, as shown in the graphic below.

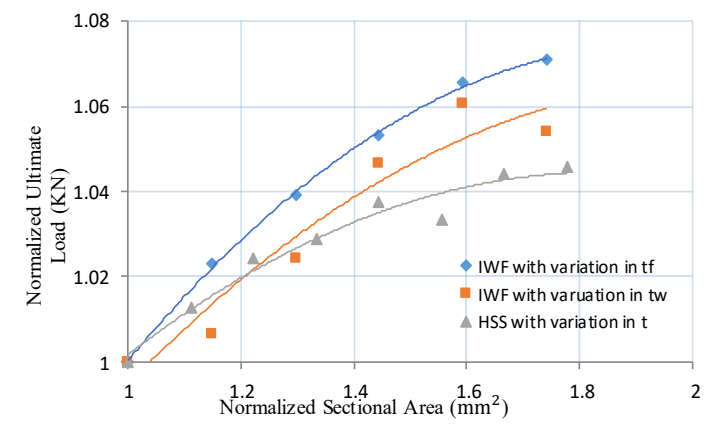

Fig. 14. Normalized Ultimate Loads vs. Section Area for Intermediate Link EBF

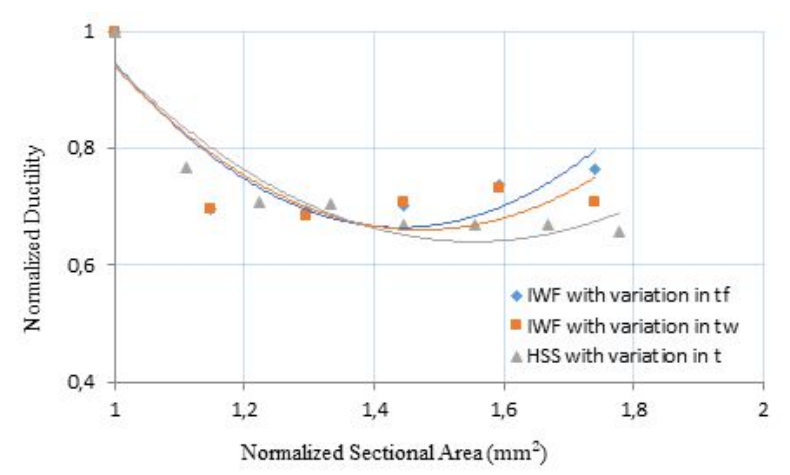

Fig. 15. Normalized Ductility vs. Section Area for Intermediate Link EBF

From the graphics above, we can see that the flange variated IWF bracing section has the best increment of ultimate loads while the web thickness variated HSS has the best value of ductility. As for the behavior of intermediate link in the increasing the bracing section, it shows quite an increase of ultimate loads an insignificant decrease of yielding displacement.

Table 4. Recapitulation of Bracing Section Variation for Long

\begin{tabular}{|c|c|c|c|c|c|c|}
\hline \multicolumn{7}{|c|}{ Link EBF } \\
\hline $\begin{array}{l}\text { Variant } \\
\end{array}$ & \multicolumn{2}{|c|}{ IWF section (mm) } & \multirow[t]{2}{*}{$\mathrm{Pu}(\mathrm{KN})$} & \multirow[t]{2}{*}{ dy $(\mathrm{mm})$} & \multirow{2}{*}{$\begin{array}{c}\mathrm{du} \\
(\mathrm{mm})\end{array}$} & \multirow[b]{2}{*}{$\mu$} \\
\hline No. & h.b.t. $\mathrm{t}_{\mathrm{w}}$ & $t_{\mathrm{f}}$ & & & & \\
\hline 41 & \multirow{6}{*}{$200.100 .5 \cdot 5 \cdot \mathrm{t}_{\mathrm{f}}$} & 8 & 582.476 & 10.000 & 35.540 & 3.554 \\
\hline 42 & & 10 & 586.039 & 10.000 & 37.375 & 3.737 \\
\hline 43 & & 12 & 586.284 & 10.000 & 37.354 & 3.735 \\
\hline 44 & & 14 & 588.827 & 10.000 & 38.094 & 3.809 \\
\hline 45 & & 16 & 592.728 & 10.000 & 40.738 & 4.074 \\
\hline 46 & & 18 & 590.766 & 10.000 & 36.046 & 3.605 \\
\hline
\end{tabular}

\begin{tabular}{|c|c|c|c|c|c|c|}
\hline \multirow{2}{*}{$\begin{array}{c}\text { Variant } \\
\text { No. }\end{array}$} & \multicolumn{2}{|c|}{ IWF section $(\mathrm{mm})$} & \multirow[t]{2}{*}{$\mathrm{Pu}(\mathrm{KN})$} & \multirow[t]{2}{*}{ dy $(\mathrm{mm})$} & \multirow{2}{*}{$\begin{array}{c}\mathrm{du} \\
(\mathrm{mm})\end{array}$} & \multirow[b]{2}{*}{$\mu$} \\
\hline & h.b.t. $\mathrm{t}_{\mathrm{f}}$ & $t_{w}$ & & & & \\
\hline 47 & \multirow{6}{*}{$200.100 . t_{\mathrm{w}} .8$} & 5.5 & 582.476 & 10.000 & 35.540 & 3.554 \\
\hline 48 & & 7.5 & 583.894 & 10.000 & 37.087 & 3.709 \\
\hline 49 & & 9.5 & 586.676 & 10.000 & 37.668 & 3.767 \\
\hline 50 & & 11.5 & 587.220 & 10.000 & 37.679 & 3.768 \\
\hline 51 & & 13.5 & 588.267 & 10.000 & 37.992 & 3.799 \\
\hline 52 & & 15.5 & 588.305 & 5.827 & 38.461 & 6.600 \\
\hline
\end{tabular}

\begin{tabular}{|c|c|c|c|c|c|c|}
\hline \multirow{2}{*}{$\begin{array}{l}\text { Variant } \\
\text { No. }\end{array}$} & \multicolumn{2}{|c|}{ IWF section $(\mathrm{mm})$} & \multirow{2}{*}{$\mathrm{Pu}(\mathrm{KN})$} & \multirow{2}{*}{ dy $(\mathrm{mm})$} & \multirow{2}{*}{$\begin{array}{c}\mathrm{du} \\
(\mathrm{mm})\end{array}$} & \multirow[b]{2}{*}{$\mu$} \\
\hline & $\mathrm{h}, \mathrm{b}$ & $t_{w}$ & & & & \\
\hline 53 & \multirow{8}{*}{$200.100 . t$} & 4.5 & 579.365 & 9.999 & 39.009 & 3.901 \\
\hline 54 & & 5 & 580.051 & 9.999 & 37.994 & 3.800 \\
\hline 55 & & 5.5 & 577.321 & 6.263 & 39.180 & 6.256 \\
\hline 56 & & 6 & 585.689 & 6.173 & 38.778 & 6.282 \\
\hline 57 & & 6.5 & 586.923 & 10.000 & 38.899 & 3.890 \\
\hline 58 & & 7 & 580.862 & 6.027 & 37.768 & 6.266 \\
\hline 59 & & 7.5 & 588.353 & 10.000 & 38.954 & 3.895 \\
\hline 60 & & 8 & 589.818 & 5.912 & 40.418 & 6.836 \\
\hline
\end{tabular}

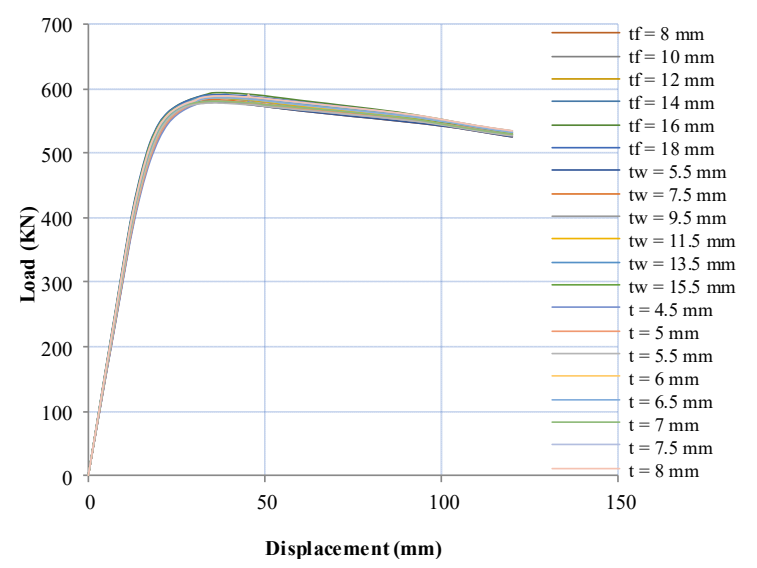

Fig. 16. Displacement vs. Load in IWF and HSS Cross-Section Profile Variated in Long Link EBF.

In the long link $\operatorname{EBF}(\mathrm{e}=2800 \mathrm{~mm})$, increasing the bracing section nor changing the profile from IWF to HSS doesn't change its ultimate loads as much as the short and intermediate link does. Almost all of the variations overlapped each other, as shown in graphic 4.7. While the lowest ultimate load for the long link is $579.365 \mathrm{kN}$, and its ultimate displacement is $39.009 \mathrm{~mm}$. The highest value of ductility in the long link is 6.836 .

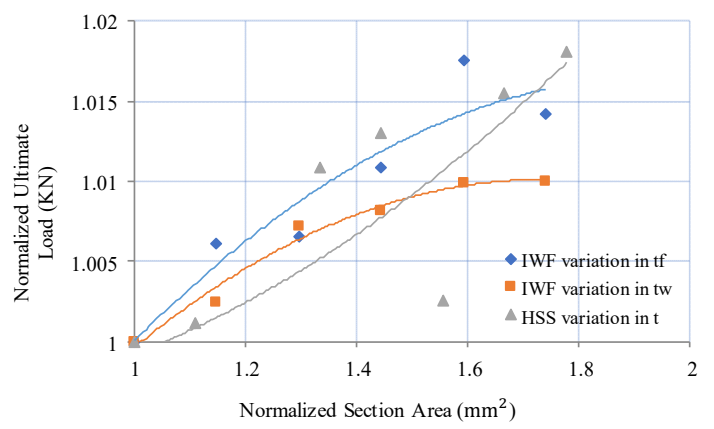

Fig. 17. Normalized Ultimate Loads vs Section Area for Long Link EBF

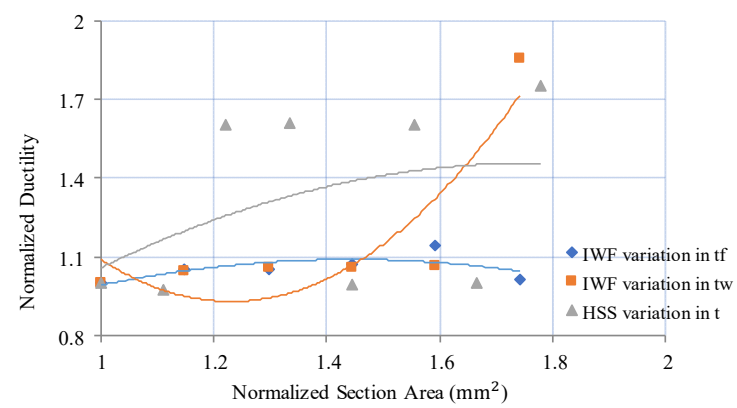

Fig. 18. Normalized Ductility vs. Section Area for Long Link $\mathrm{EBF}$ 
From the graphics above, we can see that the flange variated IWF bracing section has the best increment of ultimate loads while the web thickness variated HSS has the best value of ductility, the same as short and intermediate link's. As for the behavior of long links in the increasing the bracing section, it only shows an insignificant increase of ultimate loads.

\subsection{Analysis of IWF Bracing Flange Thickness Variation}

Variation of the flange thickness of the IWF bracing section influenced short links the most, as it has the highest point of ultimate loads (Fig. 19), with normalized ultimate loads of $1.254(1128.197 \mathrm{kN})$ compared to the base thickness of $8 \mathrm{~mm}$. Meanwhile, the long and intermediate link EBF doesn't show a significant change, with normalized ultimate loads of 1.014 for the long link and 1.756 for the intermediate link at most.

In the case of ductility (Fig. 20), the graphic shows that instead of decreasing, long link EBF's ductility value increases, the opposite of short and intermediate link EBF.

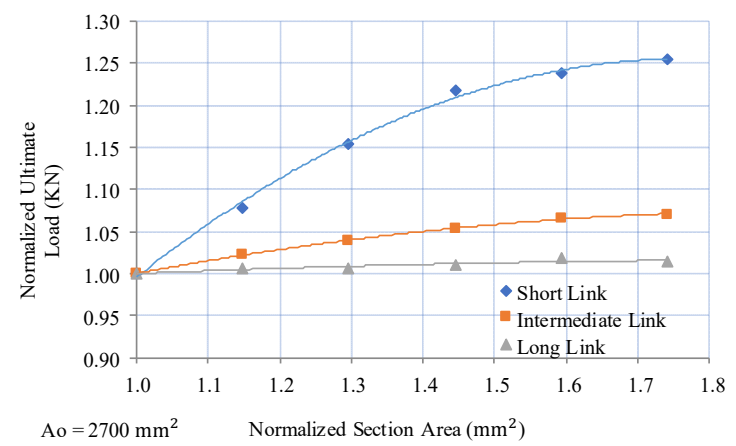

Fig. 19. Normalized Ultimate Loads vs. Section Area of IWF Flange Thickness, in Short, Intermediate and Long Link EBF

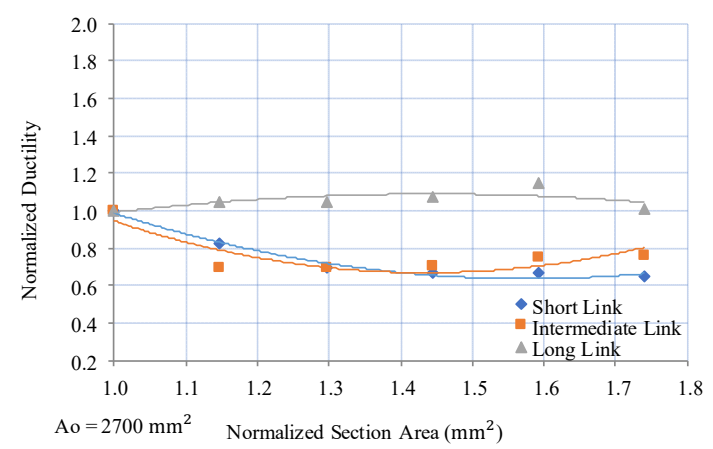

Fig. 20. Normalized Ductility vs. Section Area of IWF Flange Thickness in Short, Intermediate and Long Link EBF

\subsection{Analysis of IWF Bracing Web Thickness Variation}

Similar to IWF flange thickness variation, web thickness variation also influences the short link the most. As the bracing section area increases, the ultimate load goes up simultaneously.

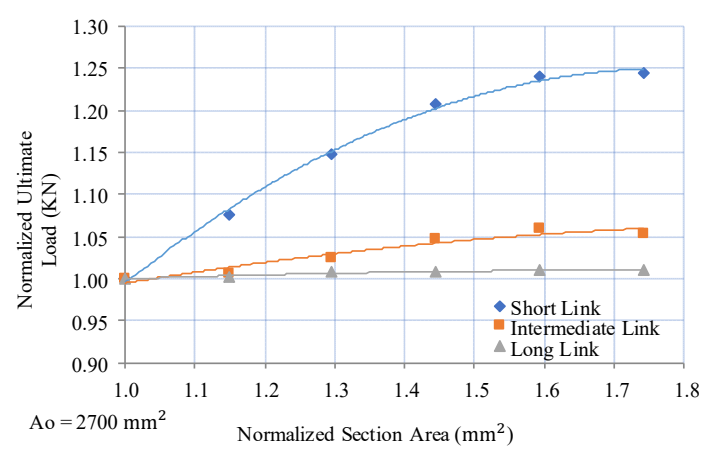

Fig. 21. Normalized Ultimate Loads vs. Section Area of IWF Web Thickness in Short, Intermediate and Long Link EBF

The intermediate link shows a bit of regression in the thickness of $18 \mathrm{~mm}$, but the highest point of ultimate load in the intermediate link is at $13.5 \mathrm{~mm}$ as the normalized number is 1.592. Long link EBF also doesn't show a significant change in the ultimate loads it has.

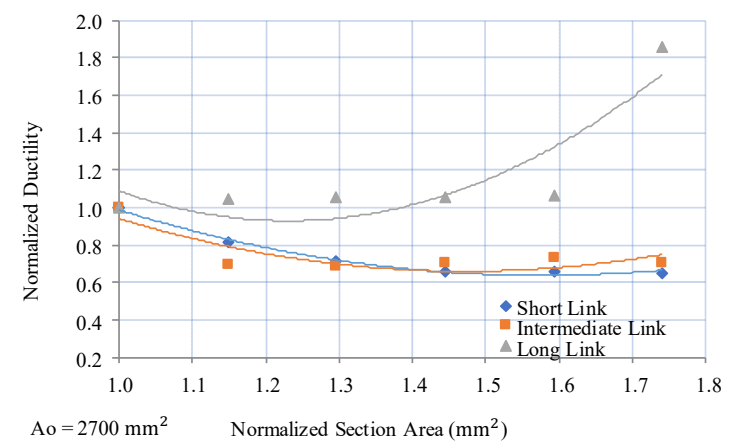

Fig. 22. Normalized Ductility vs. Section Area of IWF Web Thickness in Short, Intermediate and Long Link EBF

\subsection{Analysis of HSS Bracing Web Thickness Variation}

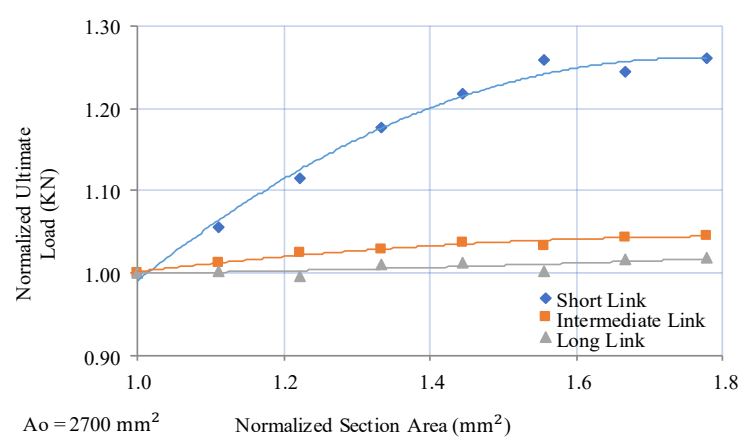

Fig. 23. Normalized Ultimate Load vs. Section Area of HSS Web Thickness in Short, Intermediate and Long Link EBF

In HSS web thickness variation, intermediate and long link EBF's ultimate load increment almost overlapped each other as they have less increment than the short link has.

It shows that HSS type bracing is less effective for intermediate and long link EBF. Although it has better ductility than IWF does, in case of ultimate loads, IWF type bracing is superior since it increases all three link types better than HSS does. 


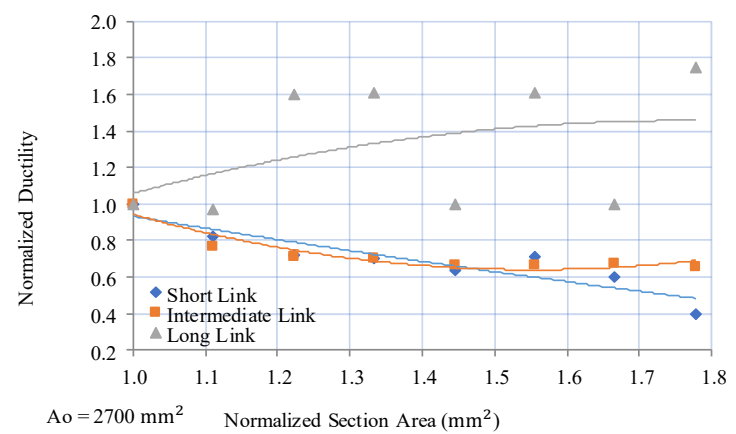

Fig. 24. Normalized Ductility vs. Section Area of HSS Web Thickness in Short, Intermediate and Long Link EBF

\section{Conclusions}

1. Variating the thickness of the bracing section affects ultimate loads, ultimate displacement, and ductility value in all types of eccentric frames. Meanwhile, increasing the bracing section's thickness increases the ultimate loads and decreases the ultimate displacement and ductility value.

2. The best bracing option for a higher ultimate load is the IWF type since it has a slightly higher increment of the ultimate load from HSS type.

3. The highest ductility value appears in HSS bracing from short, intermediate, and long link EBF. But from the three types of links, the short link has the highest ductility value over all of the variations.
4. Ductility is not bound by the increment of bracing section's thickness, whether it is IWF nor HSS bracing.

5. The structure that affected by the bracing variations is the short link, while the least affected ones are the long link EBF.

Authors thank Department of Civil Engineering, University of Andalas, for partially financial support for this research.

\section{References}

1. M. Bruneau, C.M. Uang, R. Sabelli, Ductile Design of Steel Structure, $2^{\text {nd }}$ Ed., United States: McGraw-Hill Companies, Inc (2011)

2. M. Bruneau, C.M. Uang, A.S. Whittaker, K.C. Tsai, Seismic Design of Steel Structure, United States: McGraw-Hill Companies, Inc. (2001)

3. N.B. Wirawan, J. Sci. App. Tech. 1(1) (2017)

4. G.Q. Li, J.J. Li,Advanced Analysis and Design of Steel Frames, John Wiley \& Sons,Ltd. (2007)

5. Yurisman, Nidiasari, O. Gusperi., H. Muchlis, Prosiding Seminar Nasional IV HASTAG, 101-111 (2013)

6. Yurisman, B. Budiono, M. Moestopo,M. Suarjana, J. T. Sipil 17(1) (2010) 